Article

\title{
Low-Temperature Oxidation of Dimethyl Ether to Polyoxymethylene Dimethyl Ethers over CNT-Supported Rhenium Catalyst
}

\author{
Qingde Zhang ${ }^{1}$, Wenfeng Wang ${ }^{1,2}$, Zhenzhou Zhang ${ }^{1,2}$, Yizhuo Han ${ }^{1, *}$ and Yisheng Tan ${ }^{1, *}$ \\ 1 State Key Laboratory of Coal Conversion, Institute of Coal Chemistry, Chinese Academy of Sciences, \\ Taiyuan 030001, China; qdzhang@sxicc.ac.cn (Q.Z.); wangwf@sxicc.ac.cn (W.W.); zhangzz@sxicc.ac.cn (Z.Z.) \\ 2 Graduate University of Chinese Academy of Sciences, Beijing 100049, China \\ * Correspondence: hanyz@sxicc.ac.cn (Y.H.); tan@sxicc.ac.cn (Y.T.); Tel./Fax: +86-351-404-4287 (Y.T. \& Y.H.); \\ +86-351-404-9747 (Y.T. \& Y.H.)
}

Academic Editor: Stuart H. Taylor

Received: 14 December 2015; Accepted: 3 March 2016; Published: 14 March 2016

\begin{abstract}
Due to its excellent conductivity, good thermal stability and large specific surface area, carbon nano-tubes (CNTs) were selected as support to prepare a Re-based catalyst for dimethyl ether (DME) direct oxidation to polyoxymethylene dimethyl ethers $\left(\mathrm{DMM}_{x}\right)$. The catalyst performance was tested in a continuous flow type fixed-bed reactor. $\mathrm{H}_{3} \mathrm{PW}_{12} \mathrm{O}_{40}\left(\mathrm{PW}_{12}\right)$ was used to modify Re/CNTs to improve its activity and selectivity. The effects of $\mathrm{PW}_{12}$ content, reaction temperature, gas hourly space velocity (GHSV) and reaction time on DME oxidation to $\mathrm{DMM}_{x}$ were investigated. The results showed that modification of CNT-supported Re with $30 \% \mathrm{PW}_{12}$ significantly increased the selectivity of DMM and $\mathrm{DMM}_{2}$ up to $59.0 \%$ from $6.6 \%$ with a DME conversion of $8.9 \%$; besides that, there was no $\mathrm{CO}_{x}$ production observed in the reaction under the optimum conditions of $513 \mathrm{~K}$ and $1800 \mathrm{~h}^{-1}$. The techniques of XRD, BET, $\mathrm{NH}_{3}$-TPD, $\mathrm{H}_{2}$-TPR, XPS, TEM and SEM were used to characterize the structure, surface properties and morphology of the catalysts. The optimum amount of weak acid sites and redox sites promotes the synthesis of $\mathrm{DMM}$ and $\mathrm{DMM}_{2}$ from $\mathrm{DME}$ direct oxidation.
\end{abstract}

Keywords: dimethyl ether; low-temperature oxidation; polyoxymethylene dimethyl ethers; carbon nano-tubes; $\mathrm{Re} ; \mathrm{H}_{3} \mathrm{PW}_{12} \mathrm{O}_{40}$

\section{Introduction}

Dimethyl ether $\left(\mathrm{CH}_{3} \mathrm{OCH}_{3}, \mathrm{DME}\right)$ is a clean fuel with high cetane number and is also a potential and non-petroleum route chemical synthesis material. DME can be synthesized via one-step process at low cost from syngas generated from coal, biomass and natural gas. Because of the low boiling point of DME $(246.3 \mathrm{~K})$, it is not possible to simply replace diesel with DME or directly blend DME with diesel. Polyoxymethylene dimethyl ethers $\left(\mathrm{CH}_{3} \mathrm{O}\left(\mathrm{CH}_{2} \mathrm{O}\right)_{x} \mathrm{CH}_{3}, \mathrm{DMM}_{x}\right)$ are promising diesel oil additives due to the similar structure of $-\mathrm{C}-\mathrm{O}-\mathrm{C}-\mathrm{O}-\mathrm{C}-\mathrm{O}-\mathrm{C}-$ with $\mathrm{DME}$ and high content of oxygen and cetane number [1]. The addition of DMMx to diesel oil can greatly improve the combustion and reduce particular matter emissions of diesel engines. In indusry, $\mathrm{DMM}_{x}$ is mainly produced via condensation of methanol and trioxymethylene over acidity catalysts [2], but this synthesis technology has the problems of high energy consumption, high investment and high operation cost. Utilizing oxidation of DME to synthesize $\mathrm{DMM}_{x}$ is one of the most attractive green routes for the synthesis of clean fuel additives with a short process, low $\mathrm{CO}_{2}$ emissions and high energy efficiency.

DME oxidation has been paid more and more attention due to the advantages of simplicity and feasibility [3-8]. Yagita Hirosh et al. examined DME oxidation to 1,2-dimethoxyethane (DMET) over a $\mathrm{SnO}_{2} / \mathrm{MgO}$ catalyst [9]. Wenjie Shen et al. investigated the supported $\mathrm{MoO}_{x}$ and $\mathrm{VO}_{x}$ catalysts 
for DME oxidation to HCHO [10]. Haichao Liu et al. reported that the synthesis of DMM from the oxidation of DME and methanol using $\mathrm{H}_{3+n} \mathrm{~V}_{n} \mathrm{Mo}_{12-n} \mathrm{PO}_{40}$ [11]. In recent years, our group has been focusing on the selective oxidation of DME to $\mathrm{HCHO}$, methyl formate (MF), $\mathrm{DMM}_{x}$, etc. over different catalysts [12-15].

In our previous work, a Mn- $\left(\mathrm{Sm}+\mathrm{SiW}_{12}\right) / \mathrm{SiO}_{2}$ catalyst exhibited good activity for the selective oxidation of DME to DMM at $593 \mathrm{~K}$, but by-product $\mathrm{CO}_{x}$ was usually formed due to a high reaction temperature [16]. Though the DMM synthesis from DME oxidation has been realized, further enhancing the chain growth of $\mathrm{C}-\mathrm{O}$ to obtain larger $\mathrm{DMM}_{x}$ molecules from DME direct oxidation at low temperature is still a very challenging task.

Rhenium oxide is widely used in some oxidation reactions due to its unique redox and acidic properties [17-23]. We have also found that $\mathrm{Re} / \mathrm{TiO}_{2}$ was active for the selective oxidation of DME and DMM as co-reactants to $\mathrm{DMM}_{2}$ [14]; however, the low surface area of $\mathrm{TiO}_{2}$ affects the dispersion of active components, and catalyst particles are prone to sintering during the reaction, which restrains the increase of catalyst activity. Carbon nano-tubes (CNTs) have been applied as support in catalytic reactions because of their excellent conductivity, good thermal stability and large specific surface area [24-28].

In the present study, CNTs were selected as support due to their unique surface properties. The $\mathrm{H}_{3} \mathrm{PW}_{12} \mathrm{O}_{40}\left(\mathrm{PW}_{12}\right)$, which can offer acidity, was used to modify Re/CNTs. The effects of $\mathrm{PW}_{12}$ content, reaction temperature, gas hourly space velocity (GHSV), and reaction time on DME oxidation to DMMx were investigated. The results show that the $\mathrm{PW}_{12}$-modified Re/CNTs demonstrates high activity and selectivity for the formation of $\mathrm{DMM}$ and $\mathrm{DMM}_{2}$ via DME direct oxidation at low temperature. The total selectivity of $\mathrm{DMM}$ and $\mathrm{DMM}_{2}$ reaches $59.0 \%$ with DME conversion of $8.9 \%$ at $513 \mathrm{~K}$ without $\mathrm{CO}_{x}$ formation over $5 \% \mathrm{Re}-30 \% \mathrm{PW}_{12} / \mathrm{CNTs}$. The techniques of $\mathrm{XRD}, \mathrm{BET}, \mathrm{NH}_{3}-\mathrm{TPD}$, $\mathrm{H}_{2}$-TPR, XPS, TEM and SEM are used to characterize the structure, surface properties and morphology of the catalysts. Until now, there have been no reports about the DME oxidation to DMM and $\mathrm{DMM}_{2}$ over CNT-supported Re catalyst.

\section{Results and Discussion}

\subsection{Effects of $P W_{12}$ Content on the Performance of $5 \%$ Re-PW $W_{12} / C N T s$}

Table 1 shows the selectivity and the conversion of DME as a function of $\mathrm{PW}_{12}$ content in $5 \%$ Re-PW 12 /CNTs. Over a CNT-supported Re catalyst, DME conversion is only $4.2 \%$, and DMM selectivity is as low as $6.6 \%$ and no $\mathrm{DMM}_{2}$ is found, but $\mathrm{HCHO}$ selectivity reaches $73.7 \%$, which indicates that Re/CNTs exhibits more redox sites than acid sites. When $5 \% \mathrm{PW}_{12}$ is used to modify Re/CNTs, there is an evident increase in DMM selectivity, and a trace of $\mathrm{DMM}_{2}$ is formed. After $20 \% \mathrm{PW}_{12}$ introduction to Re/CNTs, DMM selectivity is clearly increased to $45.9 \%$, and its selectivity reaches $4.1 \%$. The selectivity of $\mathrm{DMM}$ and $\mathrm{DMM}_{2}$ reaches the highest value of $59.0 \%$, and DME conversion is also increased to $8.9 \%$ when Re/CNTs is modified by $30 \% \mathrm{PW}_{12}$. However, a further increase of $\mathrm{PW}_{12}$ content leads to a decline in the selectivity of $\mathrm{DMM}_{1-2}$. Especially, when $\mathrm{PW}_{12}$ content reaches as high as $80 \%$, DME is mainly oxidized to $\mathrm{CO}$ with $64.4 \%$ selectivity. The activity and selectivity of pure $30 \% \mathrm{PW}_{12}$ before Re addition has been also investigated and the DMM selectivity of $32.7 \%$ is obtained; besides that, $\mathrm{DMM}_{2}$ selectivity reaches $13.9 \%$, but by-product $\mathrm{CO}$ is found with the selectivity of $14.6 \%$.

The results show that the addition of $\mathrm{PW}_{12}$ has obvious effects on DME conversion and DMM selectivity. It can be seen in Table 1 that no $\mathrm{CO}_{x}$ is formed in the reaction of DME to DMM and $\mathrm{DMM}_{2}$ when CNTs are used as support along with an optimum amount of $\mathrm{PW}_{12}$ introduction under the conditions of $513 \mathrm{~K}$ and $1800 \mathrm{~h}^{-1}$. This may be due to the special adsorption capacity and excellent conductivity of CNTs. 
Table 1. Effects of $\mathrm{PW}_{12}$ content on the performance of $5 \%$ Re-PW $12 / \mathrm{CNTs}$.

\begin{tabular}{|c|c|c|c|c|c|c|c|c|c|}
\hline \multirow[t]{2}{*}{ Catalysts } & \multirow{2}{*}{$\begin{array}{c}\text { DME } \\
\text { Conversion } \\
(\%)\end{array}$} & \multicolumn{8}{|c|}{$\begin{array}{l}\text { Selectivity } \\
\text { (C-mol\%) }\end{array}$} \\
\hline & & DMM & $\mathrm{DMM}_{2}$ & $\mathrm{CH}_{3} \mathrm{OH}$ & HCHO & MF & $\mathrm{CO}$ & $\mathrm{CH}_{4}$ & $\mathrm{CO}_{2}$ \\
\hline $\mathrm{Re} / \mathrm{CNTs}$ & 4.2 & 6.6 & 0 & 16.2 & 73.7 & 3.5 & 0 & 0 & 0 \\
\hline Re-5\%PW $12 / C N T s$ & 4.9 & 26.3 & 0.3 & 2.7 & 67.7 & 3.0 & 0 & 0 & 0 \\
\hline Re-20\%PW $12 / C N T s$ & 6.1 & 45.9 & 4.1 & 2.6 & 45.0 & 2.4 & 0 & 0 & 0 \\
\hline Re-30\%PW $12 / C N T s$ & 8.9 & 55.0 & 4.0 & 4.2 & 31.4 & 5.4 & 0 & 0 & 0 \\
\hline Re- $40 \% \mathrm{PW}_{12} / \mathrm{CNTs}$ & 9.5 & 50.7 & 3.7 & 4.4 & 38.9 & 2.3 & 0 & 0 & 0 \\
\hline Re- $80 \% \mathrm{PW}_{12} / \mathrm{CNT}$ & 15.0 & 27.5 & 1.7 & 3.5 & 2.1 & 0.8 & 64.4 & 0 & 0 \\
\hline $30 \% \mathrm{PW}_{12} / \mathrm{CNTs}$ & 10.0 & 32.7 & 13.9 & 16.8 & 21.4 & 0.6 & 14.6 & 0 & 0 \\
\hline
\end{tabular}

Reaction conditions: atmospheric pressure, $513 \mathrm{~K}$, cat.: $1 \mathrm{~mL}, 15 \mathrm{~min}, 1800 \mathrm{~h}^{-1}, n \mathrm{O}_{2}: n \mathrm{DME}=1: 1$.

In our previous work, a possible reaction mechanism of DME oxidation to DMM was proposed and DMM synthesis needed acid sites and redox sites [7,16]. According to the present reaction results, DMM can probably be formed by the acetalization reaction of methanol (formed by DME hydrolysis over acid sites) and $\mathrm{HCHO}$ (oxidized by $\mathrm{CH}_{3} \mathrm{OH}$ over redox sites) at low temperature. We also suggest that DMM may be the intermediate for the formation of $\mathrm{DMM}_{2}$ via DME oxidation [14]. $\mathrm{CH}_{3} \mathrm{OCH}_{2} \mathrm{OCH}_{2} \mathrm{OCH}_{3}$ may be synthesized via $\mathrm{CH}_{3} \mathrm{OCH}_{2} \mathrm{OCH}_{2}$ group (obtained after the cleavage of the terminal $\mathrm{C}-\mathrm{H}$ bond of DMM molecule over the redox sites) combining $\mathrm{CH}_{3} \mathrm{O}$ (formed over acid sites) under the cooperation of the acid sites and the redox sites of the catalyst. Therefore, optimum amount of the acid sites and redox sites of the catalyst is beneficial to the formation of DMM and $\mathrm{DMM}_{2}$ from DME oxidation.

\subsection{Effects of Reaction Temperature on the Performance of $5 \%$ Re- $30 \% P W_{12} / C N T s$}

Table 2 shows the effects of reaction temperature on DME conversion and the selectivity of DMM and $\mathrm{DMM}_{2}$ over $5 \%$ Re- $30 \% \mathrm{PW}_{12} / \mathrm{CNTs}$. With increasing reaction temperature, DME conversion keeps an upward trend because DME molecule is easily activated at higher temperatures. At $493 \mathrm{~K}$, the total selectivity of $\mathrm{DMM}$ and $\mathrm{DMM}_{2}$ is $19.8 \%$ with DME conversion of $6.6 \%$, but the $\mathrm{HCHO}$ selectivity is as high as $62.0 \%$. The selectivity of $\mathrm{DMM}$ and $\mathrm{DMM}_{2}$ reaches the highest value of $59.0 \%$, and $\mathrm{HCHO}$ selectivity clearly decreases to $31.4 \%$ when temperature is increased to $513 \mathrm{~K}$. Then, the selectivity of $\mathrm{DMM}$ and $\mathrm{DMM}_{2}$ decreases constantly with the increase in temperature. At $533 \mathrm{~K}$, the selectivity of DMM and $\mathrm{DMM}_{2}$ decreases to $49.8 \%$, and, concurrently, by-product CO appears and its selectivity is $13.2 \%$. CO selectivity reaches $21.9 \%$ when temperature is further increased to $553 \mathrm{~K}$. Lower temperature is not the optimum conditions for DME oxidation to DMM and $\mathrm{DMM}_{2}$, and $\mathrm{HCHO}$ is the main by-product. However, higher temperature easily leads to over-oxidation of DME to produce more $\mathrm{CO}$. Therefore, the optimum reaction temperature is $513 \mathrm{~K}$ for DME direct-oxidation to $\mathrm{DMM}$ and $\mathrm{DMM}_{2}$ with high $\mathrm{DMM}_{1-2}$ selectivity and low by-product selectivity.

Table 2. Effects of reaction temperature on the performance of $5 \% \operatorname{Re}-30 \% \mathrm{PW}_{12} / \mathrm{CNTs}$.

\begin{tabular}{|c|c|c|c|c|c|c|c|c|c|}
\hline \multirow{2}{*}{$\begin{array}{c}\text { Reaction } \\
\text { Temperature } \\
\text { (K) }\end{array}$} & \multirow{2}{*}{$\begin{array}{c}\text { DME } \\
\text { Conversion } \\
(\%)\end{array}$} & \multicolumn{8}{|c|}{$\begin{array}{l}\text { Selectivity } \\
\text { (C-mol\%) }\end{array}$} \\
\hline & & DMM & $\mathrm{DMM}_{2}$ & $\mathrm{CH}_{3} \mathrm{OH}$ & НCHO & MF & $\mathrm{CO}$ & $\mathrm{CH}_{4}$ & $\mathrm{CO}_{2}$ \\
\hline 493 & 6.6 & 17.0 & 2.8 & 16.5 & 62.0 & 1.7 & 0 & 0 & 0 \\
\hline 513 & 8.9 & 55.0 & 4.0 & 4.2 & 31.4 & 5.4 & 0 & 0 & 0 \\
\hline 533 & 10.9 & 45.7 & 4.1 & 4.1 & 31.1 & 1.8 & 13.2 & 0 & 0 \\
\hline 553 & 12.3 & 43.8 & 3.7 & 3.9 & 26.0 & 0.7 & 21.9 & 0 & 0 \\
\hline
\end{tabular}

Reaction conditions: atmospheric pressure, cat.: $1 \mathrm{~mL}, 15 \mathrm{~min}, 1800 \mathrm{~h}^{-1}, n \mathrm{O}_{2}: n \mathrm{DME}=1: 1$. 


\subsection{Effects of Gas Hourly Space Velocity on the Performance of $5 \%$ Re- $30 \% P W_{12} / C N T s$}

The effects of GHSV on DME oxidation to $\mathrm{DMM}_{1-2}$ over $5 \%$ Re-PW $\mathrm{PW}_{12} / \mathrm{CNTs}$ are shown in Table 3. As can be seen in Table 3, $\mathrm{CH}_{3} \mathrm{OH}$ and $\mathrm{HCHO}$ are the main products when GHSV is lower, while the higher GHSV results in higher $\mathrm{HCHO}$ selectivity. When GHSV is $1200 \mathrm{~h}^{-1}, \mathrm{CH}_{3} \mathrm{O}^{-}$from DME decomposition tends to adsorb on the acid sites of the catalyst, then $\mathrm{CH}_{3} \mathrm{OH}$ is formed and concurrently is partly oxidized to $\mathrm{HCHO}$ over redox sites, so $\mathrm{CH}_{3} \mathrm{OH}$ and $\mathrm{HCHO}$ formed as the main by-products. $\mathrm{HCHO}$ easily desorbs from the catalyst surface and has less opportunity to react with methanol to form $\mathrm{DMM}_{1-2}$ when GHSV is higher than $1800 \mathrm{~h}^{-1}$. It is proposed that HCHO may be the intermediate of $\mathrm{DMM}$ and $\mathrm{DMM}_{2}$ formation via DME direct oxidation. At a GHSV of $1800 \mathrm{~h}^{-1}, \mathrm{DMM}_{1-2}$ selectivity reaches a maximum of $59.0 \%$.

Table 3. Effects of GHSV on the performance of 5\%Re-30\%PW $12 /$ CNTs.

\begin{tabular}{|c|c|c|c|c|c|c|c|c|c|}
\hline \multirow[t]{2}{*}{ GHSV $\left(\mathbf{h}^{-1}\right)$} & \multirow{2}{*}{$\begin{array}{c}\text { DME } \\
\text { Conversion } \\
(\%)\end{array}$} & \multicolumn{8}{|c|}{$\begin{array}{l}\text { Selectivity } \\
\text { (C-mol\%) }\end{array}$} \\
\hline & & DMM & $\mathrm{DMM}_{2}$ & $\mathrm{CH}_{3} \mathrm{OH}$ & HCHO & MF & $\mathrm{CO}$ & $\mathrm{CH}_{4}$ & $\mathrm{CO}_{2}$ \\
\hline 1200 & 9.8 & 28.3 & 2.0 & 28.2 & 34.2 & 7.3 & 0 & 0 & 0 \\
\hline 1800 & 8.9 & 55.0 & 4.0 & 4.2 & 31.4 & 5.4 & 0 & 0 & 0 \\
\hline 2400 & 5.0 & 35.7 & 5.1 & 8.8 & 50.4 & 0 & 0 & 0 & 0 \\
\hline 3000 & 3.4 & 34.9 & 0.1 & 9.3 & 55.7 & 0 & 0 & 0 & 0 \\
\hline
\end{tabular}

Reaction conditions: atmospheric pressure, $513 \mathrm{~K}$, cat.: $1 \mathrm{~mL}, 15 \mathrm{~min}, n \mathrm{O}_{2}: n \mathrm{DME}=1: 1$.

\subsection{Effects of Reaction Time on the Performance of $5 \%$ Re-30\%PW $W_{12} / C N T s$}

The effects of reaction time on the conversion of DME and the selectivities of the main products over the $5 \%$ Re-30\% $\mathrm{PW}_{12} / \mathrm{CNTs}$ catalyst were investigated. As can be seen in Figure 1, the total selectivity of DMM and $\mathrm{DMM}_{2}$ reaches $59.0 \%$ at $15 \mathrm{~min}$. There is a slight decrease from $59.0 \%$ to $49.3 \%$ in the selectivity of DMM and $\mathrm{DMM}_{2}$, and DME conversion has no obvious changes during the $300-$ min reaction. The $5 \%$ Re- $30 \% \mathrm{PW}_{12} / \mathrm{CNTs}$ catalyst exhibits high initial activity.

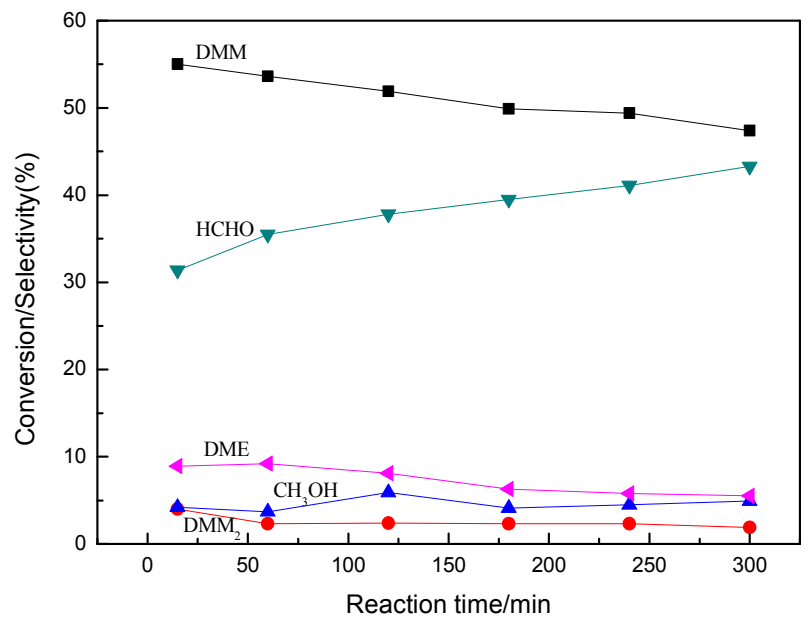

Figure 1. Effects of reaction time on the performance of $5 \%$ Re- $30 \% \mathrm{PW}_{12} / \mathrm{CNTs}$.

\subsection{Catalyst Characterization}

\subsubsection{XRD}

Figure 2 shows the XRD patterns of CNT-supported Re catalysts with different $\mathrm{PW}_{12}$ content. For the Re/CNTs catalyst, only diffraction peaks of CNTs exist and no peaks of Re oxides are found, indicating that Re oxides are highly dispersed on the catalyst surface. When $20 \% \mathrm{PW}_{12}$ is introduced to 
$\mathrm{Re} / \mathrm{CNTs}$, the diffraction peaks of $\mathrm{PW}_{12}$ appear, and the intensity of the peak becomes stronger, while the diffraction peaks of CNTs become weaker with the increase of $\mathrm{PW}_{12}$ content.

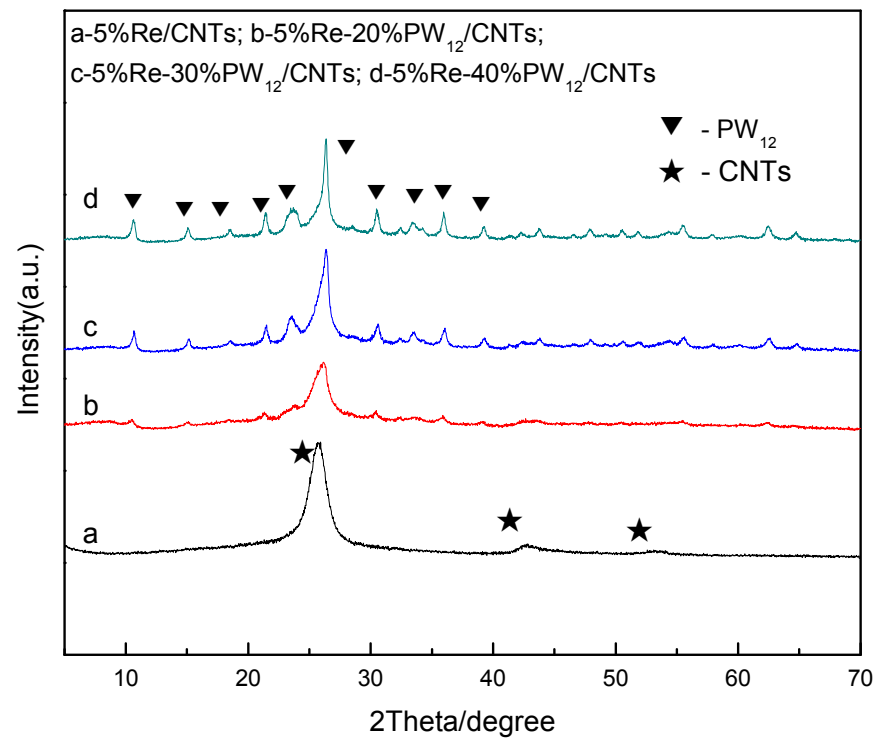

Figure 2. XRD profiles of $5 \%$ Re-PW $\mathrm{PW}_{12} / \mathrm{CNTs}$ with different $\mathrm{PW}_{12}$ content.

\subsubsection{BET Surface Area}

Table 4 shows the textural properties of CNT-supported catalysts. 5\%Re/CNTs have much larger surface area than other catalysts. $30 \% \mathrm{PW}_{12}$ introduction decreases the BET surface area of $5 \% \mathrm{Re} / \mathrm{CNTs}$ from 217.4 to $90.9 \mathrm{~m}^{2} \cdot \mathrm{g}^{-1}$ and leads to a decrease in the pore volume. It appears more obvious that the BET surface area of the catalyst decreases to $15.2 \mathrm{~m}^{2} \cdot \mathrm{g}^{-1}$ sharply, and the pore volume is only as low as $0.062 \mathrm{~cm}^{3} \cdot \mathrm{g}^{-1}$ when $80 \% \mathrm{PW}_{12}$ is introduced to Re/CNTs. This may be due to the pore blockage and the surface coverage by excessive $\mathrm{PW}_{12}$. It can be seen in Table 4 that the BET surface area of the $5 \% \operatorname{Re}-30 \% \mathrm{PW}_{12} / \mathrm{CNTs}$ catalyst decreases from 90.9 to $81.1 \mathrm{~m}^{2} \cdot \mathrm{g}^{-1} 6 \mathrm{~h}$ post-reaction.

Table 4. Textural properties of the catalysts.

\begin{tabular}{cccc}
\hline Catalysts & $\begin{array}{c}\text { BET Surface Area } \\
\boldsymbol{A}\left(\mathbf{m}^{\mathbf{2}} \cdot \mathbf{g}^{-1}\right)\end{array}$ & $\begin{array}{c}\text { Total Pore Volume } \\
\boldsymbol{v}\left(\mathbf{c m}^{\mathbf{3}} \cdot \mathbf{g}^{-1}\right)\end{array}$ & $\begin{array}{c}\text { Average Pore Diameter } \\
\boldsymbol{d}(\mathbf{n m})\end{array}$ \\
\hline $5 \%$ Re/CNTs & 217.4 & 1.054 & 19.399 \\
$5 \%$ Re-30\%PW $12 / \mathrm{CNTs}$ & 90.9 & 0.467 & 20.539 \\
$5 \%$ Re-30\%PW $12 / \mathrm{CNTs}$ & 81.1 & 0.523 & 25.795 \\
after reaction & 15.2 & 0.062 & 16.402 \\
$5 \%$ Re-80\%PW & & & \\
\hline
\end{tabular}

\subsection{3. $\mathrm{NH}_{3}-\mathrm{TPD}$}

Figure 3 shows the $\mathrm{NH}_{3}-\mathrm{TPD}$ profiles of $5 \%$ Re-PW $\mathrm{PW}_{12} / \mathrm{CNTs}$ with different $\mathrm{PW}_{12}$ content. Re/CNTs only has weak acid sites due to an $\mathrm{NH}_{3}$ desorption peak at about $430 \mathrm{~K}$. When $\mathrm{PW}_{12}$ was introduced into Re/CNTs, two $\mathrm{NH}_{3}$ desorption peaks at about 470 and $630 \mathrm{~K}$, corresponding to weak acid sites and strong acid sites, appeared respectively. In order to compare the changes of acid sites after $\mathrm{PW}_{12}$ introduction, the area of $\mathrm{NH}_{3}$ desorption peaks were integrated (see Table 5). By increasing the content of $\mathrm{PW}_{12}$, the number of the weak acid sites and the strong acid sites becomes larger. The ratio of S1(weak acid sites)/S2(strong acid sites) is highest when $\mathrm{PW}_{12}$ content is $30 \%$. According to the reaction results, the increased amount of weak acid sites can favor the formation of DMM and $\mathrm{DMM}_{2}$ from DME oxidation. 


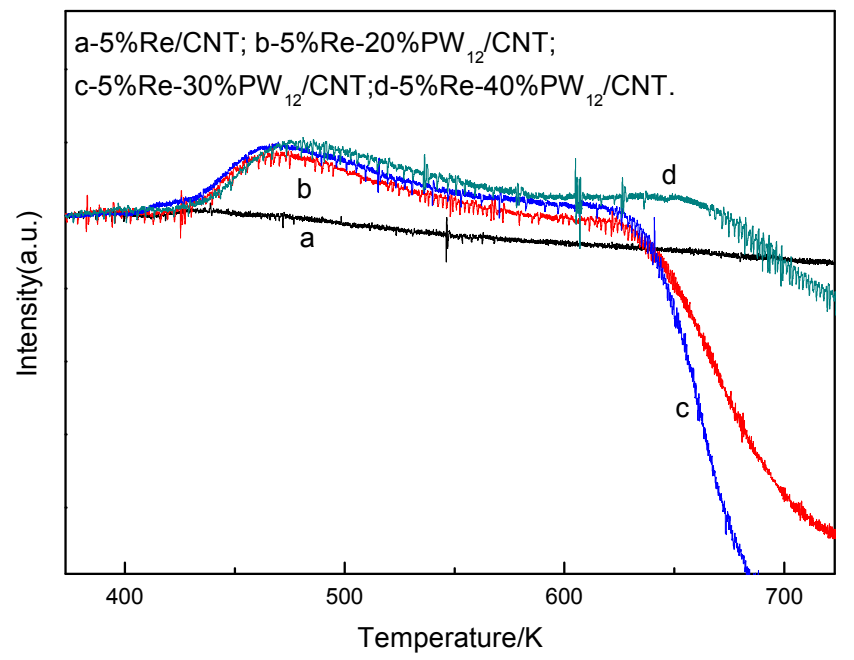

Figure 3. $\mathrm{NH}_{3}$-TPD profiles of $5 \%$ Re-PW $12 / C N T s$ with different $\mathrm{PW}_{12}$ content.

Table 5. Results of $\mathrm{NH}_{3}$-TPD integration.

\begin{tabular}{cccc}
\hline Catalysts & $\begin{array}{c}\text { Weak Acid Sites } \\
\text { Area(S1) }\end{array}$ & $\begin{array}{c}\text { Strong Acid Sites } \\
\text { Area(S2) }\end{array}$ & $\begin{array}{c}\text { Ratio } \\
\text { S1/S2 }\end{array}$ \\
\hline $5 \% \operatorname{Re} / \mathrm{CNTs}$ & 100 & - & - \\
$5 \% \operatorname{Re}-20 \% \mathrm{PW}_{12} / \mathrm{CNTs}$ & 89.8 & 10.2 & 8.8 \\
$5 \% \operatorname{Re}-30 \% \mathrm{PW}_{12} / \mathrm{CNTs}$ & 90.0 & 10.0 & 9.0 \\
$5 \% \operatorname{Re}-40 \% \mathrm{PW}_{12} / \mathrm{CNTs}$ & 86.9 & 13.1 & 6.6 \\
\hline
\end{tabular}

\subsection{4. $\mathrm{H}_{2}-\mathrm{TPR}$}

Figure 4 shows $\mathrm{H}_{2}$-TPR profiles of $5 \% \mathrm{Re}-\mathrm{PW}_{12} / \mathrm{CNTs}$ with different $\mathrm{PW}_{12}$ content. For the Re/CNTs catalyst, the peaks for $\mathrm{H}_{2}$ consumption appear at about $638 \mathrm{~K}$. An evident shift to lower temperature is observed after the introduction of $\mathrm{PW}_{12}$ into Re/CNTs, suggesting that the addition of $\mathrm{PW}_{12}$ can significantly facilitate the reduction of Re oxide species. When the $\mathrm{PW}_{12}$ content is $30 \%$, the temperature of reduction peak reaches its lowest value at $509 \mathrm{~K}$, which suggests that $5 \% \mathrm{Re}-30 \% \mathrm{PW}_{12} / \mathrm{CNTs}$ exhibit strong redox ability. The interaction of $\mathrm{PW}_{12}$ and the surface Re species increases the reducibility of Re-PW 12 /CNTs, consistent with the results of the introduction of $\mathrm{PO}_{4}{ }^{3-}$ and $\mathrm{SO}_{4}{ }^{2-}$, affecting the reducibility of $\mathrm{VO}_{x} / \mathrm{TS}-1$ [29].

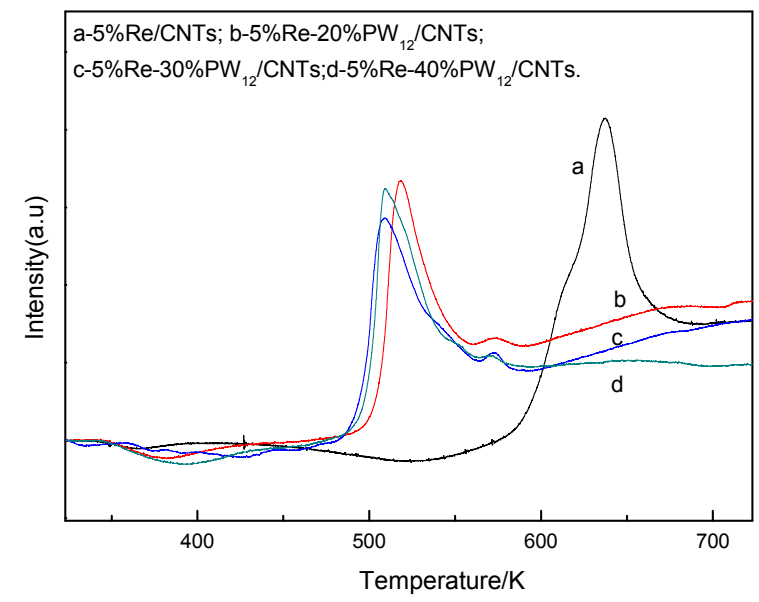

Figure 4. $\mathrm{H}_{2}$-TPR profiles of $5 \%$ Re-PW 12 /CNTs with different $\mathrm{PW}_{12}$ content. 


\subsubsection{XPS}

Figure 5 shows the Re $4 \mathrm{f}$ and O1s XPS spectra of the $5 \% \operatorname{Re} / \mathrm{CNTs}$ and $5 \% \operatorname{Re}-30 \% \mathrm{PW}_{12} / \mathrm{CNTs}$ catalysts. In contrast, a peak at $45.6 \mathrm{eV}$ is found over the $5 \%$ Re/CNTs catalyst, which should ascribe to the $\operatorname{Re} 4 f_{7 / 2}$ level for $\operatorname{Re}^{7+}$ species, indicating that $\operatorname{Re}^{7+}$ species were mainly present on the surface of $\mathrm{Re} / \mathrm{CNTs}[20,23]$. However, in our previous XPS study, $\mathrm{Re}^{7+}$ was observed at $46.6 \mathrm{eV}$ over $5 \% \mathrm{Re} / \mathrm{TiO}_{2}$. This also indicates that the existence form of Re species changes due to the different interaction of Re and support. However, when $\mathrm{PW}_{12}$ is introduced to Re/CNTs, the most remarkable change is the appearance of a peak at $41.9 \mathrm{eV}$ assigned to $\mathrm{Re}^{4+}$ species [20,23]. This suggests a strong interaction between Re oxide species and the surface of CNTs in line with the results of TPR, which indicates that the introduction of $\mathrm{PW}_{12}$ evidently changes the surface properties of CNTs and further facilitates the formation of $\mathrm{Re}^{4+}$ species. Additionally, the intensity of O1s has an obvious change before and after $\mathrm{PW}_{12}$ introduction. This further proves that the species of Re oxides are changed by $\mathrm{PW}_{12}$. Combined with the reaction results, the presence of both $\mathrm{Re}^{4+}$ and $\mathrm{Re}^{7+}$ species are further proved to promote the formation of $\mathrm{DMM}$ and $\mathrm{DMM}_{2}$.

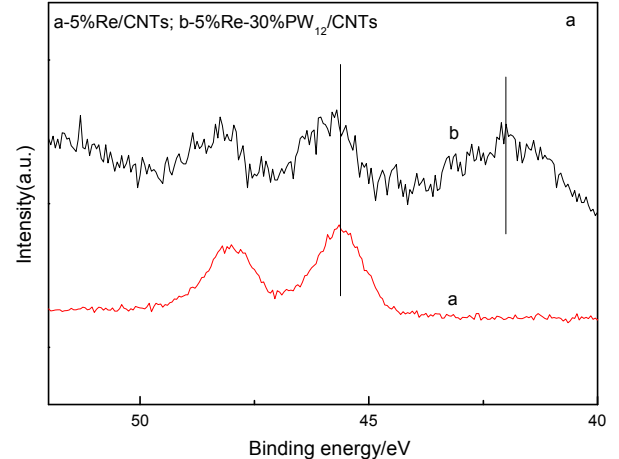

(a)

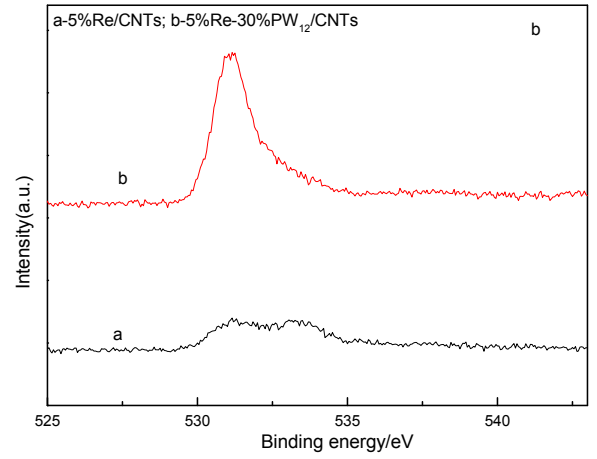

(b)

Figure 5. Re 4f (a) and O1s; (b) XPS spectra for 5\%Re/CNTs and 5\%Re-30\%PW $12 / C N T s$.

\subsubsection{TEM}

Figure 6 demonstrates the TEM images of $5 \% \operatorname{Re} / \mathrm{CNTs}, 5 \% \operatorname{Re}-30 \% \mathrm{PW}_{12} / \mathrm{CNTs}$ before and after the catalytic oxidation of DME at $513 \mathrm{~K}$ and $5 \% \mathrm{Re}-80 \% \mathrm{PW}_{12} / \mathrm{CNTs}$. Figure 6 conveys that there are distinctive differences in the images between $5 \% \operatorname{Re} / \mathrm{CNTs}$ and $5 \% \operatorname{Re}-30 \% \mathrm{PW}_{12} / \mathrm{CNTs}$ catalysts. Over $5 \% \operatorname{Re} / C N T s$, no $\mathrm{ReO}_{x}$ is found due to highly dispersed Re species over the surface of CNTs. It can be seen that the inner pores of CNTs are filled with $\mathrm{PW}_{12}$ after $30 \% \mathrm{PW}_{12}$ introduction, and, especially, $\mathrm{ReO}_{x}$ particles are clearly found over the outer surface of CNTs and the particle size of $\mathrm{ReO}_{x}$ is about $0.7 \mathrm{~nm}$. After reaction, the sample shows some agglomeration of $\mathrm{PW}_{12}$ and Re species. When $\mathrm{PW}_{12}$ content is increased to $80 \%$, excessive $\mathrm{PW}_{12}$ clearly deposits not only on the inner surface, but also the outer surface of CNTs.
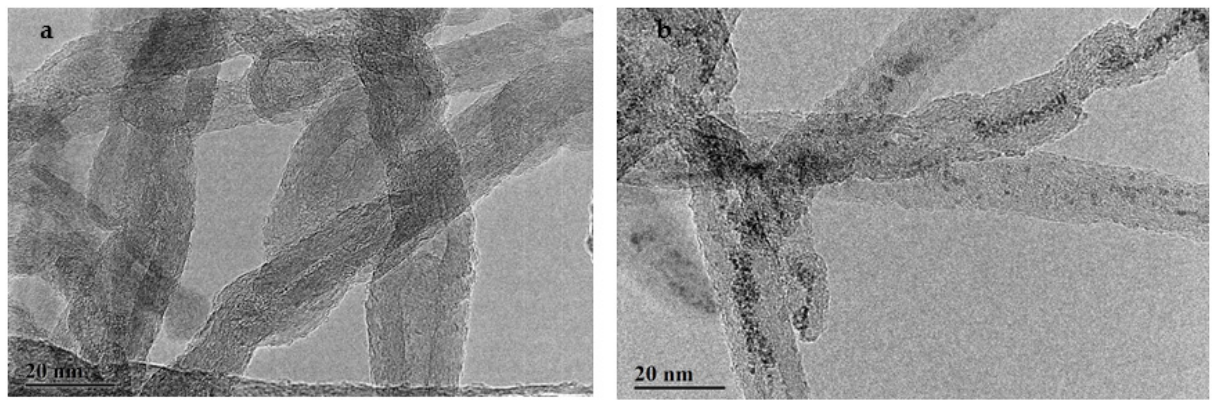

Figure 6. Cont. 

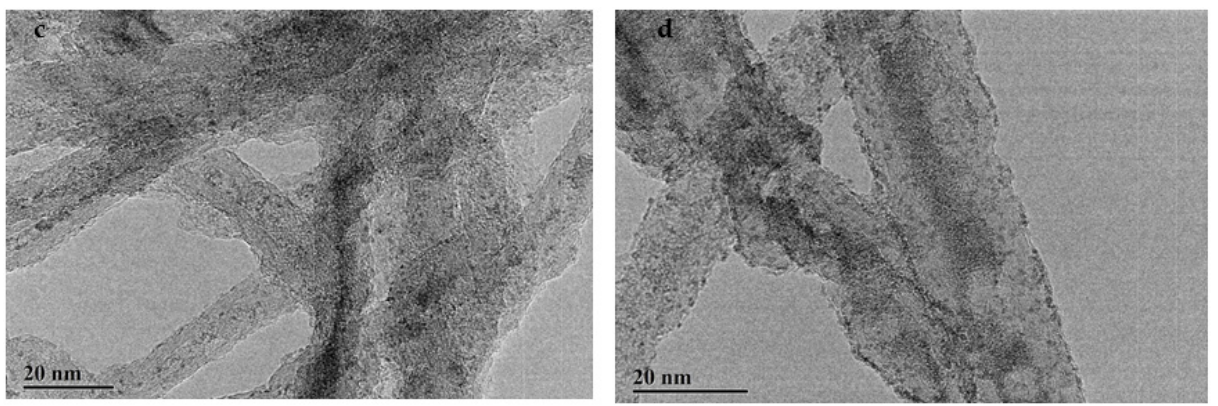

Figure 6. TEM images of 5\%Re/CNTs (a); $5 \% \operatorname{Re}-30 \% \mathrm{PW}_{12} / \mathrm{CNTs}(\mathbf{b}) ; 5 \% \operatorname{Re}-30 \% \mathrm{PW}_{12} / \mathrm{CNTs} 6 \mathrm{~h}$ post-reaction (c) and $5 \% \operatorname{Re}-80 \% \mathrm{PW}_{12} / \mathrm{CNTs}(\mathbf{d})$.

\subsubsection{SEM}

The SEM micrographs of 5\%Re/CNTs, 5\%Re-30\%PW $12 / \mathrm{CNTs}, 5 \% \operatorname{Re}-30 \% \mathrm{PW}_{12} / \mathrm{CNTs} 6 \mathrm{~h}$ post-reaction and $5 \%$ Re- $80 \% \mathrm{PW}_{12} / \mathrm{CNTs}$ catalysts are demonstrated in Figure 7 . It can be seen in Figure 7 that $\mathrm{PW}_{12}$ also exists over the outer surface of CNTs (TEM has proved that $\mathrm{PW}_{12}$ can enter the inner surface of CNTs) after $30 \% \mathrm{PW}_{12}$ introduction to Re/CNTs. After reaction, the catalyst particles tend to aggregate, leading to the decrease of BET surface area (Table 4). In evidence, $\mathrm{PW}_{12}$ and CNTs agglomerated almost completely due to the excessive introduction of $\mathrm{PW}_{12}\left(80 \% \mathrm{PW}_{12}\right)$. Combined with the TEM results, $\mathrm{PW}_{12}$ prefers to enter the inner pores of CNTs when $\mathrm{PW}_{12}$ content is low, while $\mathrm{PW}_{12}$ mainly deposits on the outer surface of CNTs along with the increase of $\mathrm{PW}_{12}$ content.


Figure 7. SEM images of 5\%Re/CNTs (a); $5 \% \operatorname{Re}-30 \% \mathrm{PW}_{12} / \mathrm{CNTs}(\mathbf{b}) ; 5 \% \operatorname{Re}-30 \% \mathrm{PW}_{12} / \mathrm{CNTs} 6 \mathrm{~h}$ post-reaction (c) and 5\%Re- $80 \% \mathrm{PW}_{12} / \mathrm{CNTs}(\mathrm{d})$.

For the $5 \% \operatorname{Re} / \mathrm{CNTs}$ catalyst, $\mathrm{ReO}_{x}$ is dispersed uniformly on the surface of CNTs according to the results of XRD and TEM. According to the results of XPS, Re species mainly exists in the form of 
$\mathrm{Re}_{2} \mathrm{O}_{7}$. After $\mathrm{PW}_{12}$ introduction to Re/CNTs, $\mathrm{PW}_{12}$ dispersed on the inner and outer surface of CNTs and affected the dispersion of $\mathrm{ReO}_{x}$ on the surface of CNTs. The introduction of optimum amount of $\mathrm{PW}_{12}$ not only increased the total amount of acid sites, but also significantly changed the oxidation state of Re species and facilitated the formation of $\mathrm{Re}^{4+}$ species. The characterization of the catalysts before and after reaction indicated that the agglomeration of active species may be the main reasons of the catalyst deactivation.

Due to the high stability of the DME molecule, the activation of DME molecule at lower temperature is very difficult, while a higher temperature easily leads to the bond-breaking of $\mathrm{C}-\mathrm{O}$ and $\mathrm{C}-\mathrm{H}$ concurrently, and further results in the complex products along with $\mathrm{CO}_{x}$ production. Therefore, how to activate DME at a lower temperature and selectively convert DME to target chemicals without $\mathrm{CO}_{x}$ formation is a challenging task. $\mathrm{DMM}_{x}$ selectivity is a very important factor for the DME highly selective oxidation to a diesel oil additive. The higher $\mathrm{DMM}_{x}$ selectivity is, the better DME utilization is, provided that no $\mathrm{CO}_{x}$ is produced during DME oxidation reactions. As the main products, $\mathrm{DMM}_{x}$, $\mathrm{HCHO}$ and $\mathrm{CH}_{3} \mathrm{OH}$ can be separated by distillation according to their different boiling points. In the present work, the low-temperature oxidation of DME to $\mathrm{DMM}_{x}$ with high $\mathrm{DMM}_{x}$ selectivity of $59.0 \%$ and DME conversion of $8.9 \%$ was realized with no $\mathrm{CO}_{x}$ production over the $5 \% \mathrm{Re}-30 \% \mathrm{PW}_{12} / \mathrm{CNTs}$. We should manage to increase $\mathrm{DMM}_{x}$ selectivity in our future work based on previous results. The conversion of DME is not too high, but increasing the DME conversion easily leads to more by-products. For the $5 \%$ Re-30\% $\mathrm{PW}_{12} / \mathrm{CNTs}$ catalyst, enhancing the $\mathrm{PW}_{12}$ content, increasing reaction temperature and decreasing GHSV can raise the DME conversion; however, $\mathrm{DMM}_{x}$ selectivity decreases clearly, and $\mathrm{CO}_{x}$ is also produced. Combining the reaction results, the $5 \% \mathrm{Re}-30 \% \mathrm{PW}_{12} / \mathrm{CNTs}$ catalyst has some advantages if it can be used in the related field in the future. The reaction temperature is $80 \mathrm{~K}$ lower than that reported in our previous work; more importantly, no $\mathrm{CO}_{x}$ was formed over $5 \% \mathrm{Re}-30 \% \mathrm{PW}_{12} / \mathrm{CNTs}$. Additionally, the catalyst stability was also increased, compared to the catalyst in the previous work. Though the once-through DME conversion is not very high, the unconverted DME can be recycled to improve its utilization. These promising results can help us thoroughly understand the reaction mechanism of DME activation and offer further possible industrial applications in the future.

\section{Experimental Section}

\subsection{Catalyst Preparation}

$\mathrm{H}_{3} \mathrm{PW}_{12} \mathrm{O}_{40}$-modified Re/CNTs catalysts were prepared by the incipient wetness impregnation method. An aqueous solution of $\mathrm{H}_{3} \mathrm{PW}_{12} \mathrm{O}_{40}$ (Shanghai Chemical Co., Shanghai, China) was impregnated in CNTs ((Multi-walled carbon nanotubes, inner diameter $=4-8 \mathrm{~nm}$, outer diameter $<10-20 \mathrm{~nm}$, Chengdu Organic Chemicals Co. Ltd., Chengdu, China). Raw CNTs were refluxed in $\mathrm{HNO}_{3}$ (68 wt. \%) for $14 \mathrm{~h}$ at $140{ }^{\circ} \mathrm{C}$ in an oil bath; then the mixture was filtered and washed with deionized water, followed by drying at $60{ }^{\circ} \mathrm{C}$ for $12 \mathrm{~h}$.) at $298 \mathrm{~K}$ for $6 \mathrm{~h}$, then dried overnight at $393 \mathrm{~K}$, and calcined at $673 \mathrm{~K}$ for $4 \mathrm{~h}$. An aqueous solution of ammonium perrhenate $\left(\mathrm{NH}_{4} \mathrm{ReO}_{4}\right.$, Strem Chemicals, Inc., Newburyport, MA, USA) was used to impregnate the $\mathrm{H}_{3} \mathrm{PW}_{12} \mathrm{O}_{40} / \mathrm{CNTs}$, and the following procedures were the same as the above. The catalyst was designated as $5 \% \operatorname{Re}-20 \% \mathrm{PW}_{12} / \mathrm{CNTs}$, $5 \% \operatorname{Re}-30 \% \mathrm{PW}_{12} / \mathrm{CNTs}$, and $5 \% \operatorname{Re}-40 \% \mathrm{PW}_{12} / \mathrm{CNTs}$. Re/CNTs was prepared according to the above procedures. For the catalysts used in this study, Re and $\mathrm{PW}_{12}$ refer to $\mathrm{Re}_{2} \mathrm{O}_{7}$ and $\mathrm{H}_{3} \mathrm{PW}_{12} \mathrm{O}_{40}$, respectively. The amount of $\mathrm{Re}$ in the catalyst refers to the amount of $\mathrm{Re}_{2} \mathrm{O}_{7}$.

\subsection{Catalytic Oxidation of DME}

The catalytic oxidation of DME was carried out in a continuous flow type fixed-bed reactor. The catalyst ( $1 \mathrm{~mL}, 20-40$ mesh) was diluted with ground quartz to prevent the over-heating of the catalyst due to exothermic reaction. The catalyst was treated in flow of $\mathrm{O}_{2}(30 \mathrm{~mL} / \mathrm{min})$ for $1 \mathrm{~h}$ before reaction. The reactant mixture consisted of $\mathrm{DME}$ and $\mathrm{O}_{2}$ with ratio of $n \mathrm{O}_{2}: n \mathrm{DME}=1: 1$. The reaction products were analyzed by gas chromatography GC-2014CPF/SPL (Shimadzu Co., Kyoto, Japan) 
equipped with a flame ionization detector $(60 \mathrm{~m} \times 0.25 \mathrm{~mm}$, DB-1 column, Agilent Technologies Inc., Palo Alto, IA, USA) and GC-2014 (Shimadzu Co., Kyoto, Japan) with a thermal conductivity detector (Porapak T column, Waters Corporation, Milford, MA, USA). GC-4000A (TDX-01 column, East \& West Analytical Instruments, Inc., Beijing, China) with thermal conductivity detectors was used to analyze $\mathrm{H}_{2}, \mathrm{CO}, \mathrm{CO}_{2}$ and $\mathrm{CH}_{4}$.

The data of the whole work was calculated based on carbon balance, and the carbon balances of most experiments were within $95 \%-99 \%$.

\subsection{Structure and Properties Characterization}

\subsubsection{BET Surface Area}

Surface areas of the samples were measured by a BET nitrogen adsorption method at $77.35 \mathrm{~K}$ using a TriStar 300 machine (Micromeritics, Atlanta, GA, USA). The samples were treated at $473 \mathrm{~K}$ under vacuum conditions for $8 \mathrm{~h}$ before BET test.

\subsubsection{X-ray Diffraction (XRD)}

XRD patterns were measured on a Bruker Advanced X-Ray Solutions/D8-Advance (Bruker, Karlsruhe, Germany) using $\mathrm{Cu}$ Ka radiation. The anode was operated at $40 \mathrm{kV}$ and $40 \mathrm{~mA}$. The 2-Theta angles were scanned from $5^{\circ}$ to $70^{\circ}$.

\subsubsection{Temperature Programmed Desorption (TPD)}

The $\mathrm{NH}_{3}$-TPD profiles were obtained in a fixed-bed reactor system connected with a thermal conductivity detector (Tianjin Xianquan Co. Ltd., Tianjin, China). The catalyst sample (100 mg) was pretreated at $673 \mathrm{~K}$ under $\mathrm{N}_{2}$ flow $\left(40 \mathrm{~mL} / \mathrm{min}\right.$ ) for $2 \mathrm{~h}$ and then cooled down to $373 \mathrm{~K}$ under $\mathrm{N}_{2}$ flow. Then $\mathrm{NH}_{3}$ of $40 \mathrm{~mL} / \mathrm{min}$ was introduced into the flow system for a continuous $20 \mathrm{~min}$ before doing TPD. The dose amount of $\mathrm{NH}_{3}$ maintained the same for all the samples investigated. The TPD profiles were recorded at a temperature rising rate of $5 \mathrm{~K} / \mathrm{min}$ from 373 to $923 \mathrm{~K}$.

\subsubsection{Temperature Programmed Reduction (TPR)}

$\mathrm{H}_{2}$-TPR was conducted in a fixed-bed reactor system equipped with a thermal conductivity detector (Tianjin Xianquan Co. Ltd., Tianjin, China). The sample (100 mg) was pretreated in Ar at $673 \mathrm{~K}$ for $0.5 \mathrm{~h}$ and then cooled down to $323 \mathrm{~K}$. After that, a $10 \% \mathrm{H}_{2} / \mathrm{Ar}$ mixed gas was switched on and the temperature was increased linearly at a rate of $5 \mathrm{~K} / \mathrm{min}$ from $323 \mathrm{~K}$ to $923 \mathrm{~K}$.

\subsubsection{X-ray Photoelectron Spectra (XPS)}

XPS were measured on a XPS-AXIS Ultra of Kratos Co. (Manchester, UK) by using Mg Ka radiation $(\mathrm{Hv}=1253.6 \mathrm{eV})$ with $\mathrm{X}$-ray power of $225 \mathrm{~W}(15 \mathrm{kV}, 15 \mathrm{~mA})$.

\subsubsection{Transmission Electron Microscope (TEM)}

TEM images were taken on a JEM-2010 Transmission electron microscope (JEOL Company, Tokyo, Japan).

\subsubsection{Scanning Electron Microscope (SEM)}

SEM images were taken on a JSM-35C scanning electron microscope (JEOL Company, Tokyo, Japan) operated at $25 \mathrm{kV}$.

\section{Conclusions}

Low-temperature oxidation of $\mathrm{DME}$ to $\mathrm{DMM}$ and $\mathrm{DMM}_{2}$ was successfully realized over a CNT-supported Re-based catalyst. The introduction of $\mathrm{PW}_{12}$ markedly increases the activity of 
Re/CNTs. The total selectivity of DMM and $\mathrm{DMM}_{2}$ reaches $59.0 \%$ with DME conversion of $8.9 \%$ at $513 \mathrm{~K}$ without the formation of $\mathrm{CO}_{x}$ over $5 \%$ Re- $30 \% \mathrm{PW}_{12} / \mathrm{CNTs}$. CNTs as support play an important role in promoting the synthesis of $\mathrm{DMM}_{x}$ and inhibiting the formation of $\mathrm{CO}_{x}$ due to its unique physical and chemical properties.

Acknowledgments: This work was supported by the National Natural Science Foundation of China (No. 21373253, No. 20903114) and Youth Innovation Promotion Association CAS (No. 2014155).

Author Contributions: Qingde Zhang performed experiments and wrote the paper; Wenfeng Wang and Zhenzhou Zhang characterized the catalysts; Yisheng Tan and Yizhuo Han conceived the experiments and revised the paper.

Conflicts of Interest: The authors declare no conflict of interest.

\section{References}

1. Wu, J.B.; Zhu, H.Q.; Wu, Z.W.; Qin, Z.F.; Yan, L.; Du, B.L.; Fan, W.B.; Wang, J.G. High Si/Al ratio HZSM-5 zeolite: An efficient catalyst for the synthesis of polyoxymethylene dimethyl ethers from dimethoxymethane and trioxymethylene. Green Chem. 2015, 17, 2353-2357. [CrossRef]

2. Zhao, Q.; Wang, H.; Qin, Z.F.; Wu, Z.W.; Wu, J.B.; Fan, W.B.; Wang, J.G. Synthesis of polyoxymethylene dimethyl ethers from methanol and trioxymethylene with molecular sieves as catalysts. J. Fuel Chem. Tech. 2011, 39, 918-923. [CrossRef]

3. Liu, H.C.; Cheung, P.; Iglesia, E. Structure and support effects on the selective oxidation of dimethyl ether to formaldehyde catalyzed by $\mathrm{MoO}_{x}$ domains. J. Catal. 2003, 217, 222-232. [CrossRef]

4. Guo, H.J.; Sun, W.T.; Haas, F.M.; Farouk, T.; Dryer, F.L.; Ju, Y.G. Measurements of $\mathrm{H}_{2} \mathrm{O}_{2}$ in low temperature dimethyl ether oxidation. P. Combust. Inst. 2013, 34, 573-581. [CrossRef]

5. Liu, H.C.; Iglesia, E. Selective oxidation of dimethyl ether to formaldehyde on small molybdenum oxide domains. J. Catal. 2002, 208, 1-5. [CrossRef]

6. Yu, L.; Xu, J.Y.; Sun, M.; Wang, X.T. Catalytic oxidation of dimethyl ether to hydrocarbons over $\mathrm{SnO}_{2} / \mathrm{MgO}$ and $\mathrm{SnO}_{2} / \mathrm{CaO}$ catalysts. J. Nat. Gas. Chem. 2007, 16, 200-203. [CrossRef]

7. Zhang, Q.D.; Tan, Y.S.; Yang, C.H.; Han, Y.Z. $\mathrm{MnCl}_{2}$ modified $\mathrm{H}_{4} \mathrm{SiW}_{12} \mathrm{O}_{40} / \mathrm{SiO}_{2}$ catalysts for catalytic oxidation of dimethyl ether to dimethoxymethane. J. Mole. Catal. A 2007, 263, 149-155. [CrossRef]

8. Liu, G.B.; Zhang, Q.D.; Han, Y.Z.; Tsubaki, N.; Tan, Y.S. Selective oxidation of dimethyl ether to methyl formate over trifunctional $\mathrm{MoO}_{3}-\mathrm{SnO}_{2}$ catalyst under mild conditions. Green Chem. 2013, 15, 1501-1504. [CrossRef]

9. Yagita, H.; Asami, K.; Muramatsu, A. Oxidative dimerization of dimethyl ether with solid catalysts. Appl. Catal. 1989, 53, L5-L9. [CrossRef]

10. Huang, X.M.; Liu, J.L.; Chen, J.L.; Xu, Y.D.; Shen, W.J. Mechanistic study of selective oxidation of dimethyl ether to formaldehyde over alumina-supported molybdenum oxide catalyst. Catal. Lett. 2006, 108, 79-86. [CrossRef]

11. Liu, H.C.; Iglesia, E. Selective One-Step Synthesis of dimethoxymethane via methanol or dimethyl ether oxidation on $\mathrm{H}_{3+n} \mathrm{~V}_{n} \mathrm{Mo}_{12-n} \mathrm{PO}_{40}$ Keggin Structures. J. Phys. Chem. B 2003, 107, 10840-10847. [CrossRef]

12. Liu, G.B.; Zhang, Q.D.; Han, Y.Z.; Tsubaki, N.; Tan, Y.S. Effects of $\mathrm{MoO}_{3}$ structure of Mo-Sn catalysts on dimethyl ether oxidation to methyl formate under mild conditions. Green Chem. 2015, 17, 1057-1064. [CrossRef]

13. Zhang, Z.Z.; Zhang, Q.D.; Jia, L.Y.; Wang, W.F.; Zhang, T.; Han, Y.Z.; Tsubaki, N.; Tan, Y.S. Effects of tetrahedral molybdenum oxide species and $\mathrm{MoO}_{x}$ domains on the selective oxidation of dimethyl ether under mild conditions. Catal. Sci. Technol. 2016. [CrossRef]

14. Zhang, Q.D.; Tan, Y.S.; Liu, G.B.; Zhang, J.F.; Han, Y.Z. Rhenium oxide modified $\mathrm{H}_{3} \mathrm{PW}_{12} \mathrm{O}_{40} / \mathrm{TiO}_{2}$ catalysts for selective oxidation of dimethyl ether to dimethoxy dimethyl ether. Green Chem. 2014, 16, 4708-4715. [CrossRef]

15. Zhang, Q.D.; Tan, Y.S.; Yang, C.H.; Han, Y.Z. Research on catalytic oxidation of dimethyl ether to dimethoxymethane over $\mathrm{MnCl}_{2}$ modified heteropolyacid catalysts. Catal. Commun. 2008, 9, 1916-1919. [CrossRef] 
16. Zhang, Q.D.; Tan, Y.S.; Liu, G.B.; Yang, C.H.; Han, Y.Z. Promotional effects of $\mathrm{Sm}_{2} \mathrm{O}_{3}$ on $\mathrm{Mn}-\mathrm{H}_{4} \mathrm{SiW}_{12} \mathrm{O}_{40} / \mathrm{SiO}_{2}$ catalyst for dimethyl ether direct-oxidation to dimethoxymethane. J. Ind. Eng. Chem. 2014, 20, 1869-1874. [CrossRef]

17. Liu, H.C.; Gaigneaux, E.M.; Imoto, H.; Shido, T.; Iwasawa, Y. Novel Re-Sb-O catalysts for the selective oxidation of isobutene and isobutylene. Appl. Catal. A 2000, 202, 251-264. [CrossRef]

18. Yuan, Y.Z.; Liu, H.C.; Imoto, H.; Shido, T.; Iwasawa, Y. Performance and characterization of a new crystalline $\mathrm{SbRe}_{2} \mathrm{O}_{6}$ catalyst for selective oxidation of methanol to methylal. J. Catal. 2000, 195, 51-61. [CrossRef]

19. Salameh, A.; Joubert, J.; Baudouin, A.; Lukens, W.; Delbecq, F.; Sautet, P.; Basset, J.M.; Coperet, C. $\mathrm{CH}_{3} \mathrm{ReO}_{3}$ on $\gamma-\mathrm{Al}_{2} \mathrm{O}_{3}$ : Understanding its structure, initiation, and reactivity in olefin metathesis. Angew. Chew. Int. Edit. 2007, 46, 3870-3873. [CrossRef] [PubMed]

20. Yuan, Y.Z.; Iwasawa, Y. Performance and characterization of supported rhenium oxide catalysts for selective oxidation of methanol to methylal. J. Phys. Chem. B 2002, 106, 4441-4449. [CrossRef]

21. Kusakari, T.; Sasaki, T.; Iwasawa, Y. Selective oxidation of benzene to phenol with molecular oxygen on rhenium/zeolite catalysts. Chem. Commun. 2004, 8, 992-993. [CrossRef] [PubMed]

22. Yuan, Y.Z.; Shido, T.; Iwasawa, Y. The new catalytic property of supported rhenium oxides for selective oxidation of methanol to methylal. Chem. Commun. 2000, 15, 1421-1422. [CrossRef]

23. Nikonova, O.A.; Capron, M.; Fang, G.; Faye, J.; Mamede, A.S.; Jalowiecki-Duhamel, L.; Dumeignil, F.; Seisenbaeva, G.A. Novel approach to rhenium oxide catalysts for selective oxidation of methanol to DMM. J. Catal. 2011, 279, 310-318. [CrossRef]

24. Zhang, F.; Ren, P.J.; Pan, X.L.; Liu, J.Y.; Li, M.R.; Bao, X.H. Self-Assembly of atomically thin and unusual face-centered cubic Re nanowires within carbon nanotubes. Chem. Mater. 2015, 27, 1569-1573. [CrossRef]

25. Ugarte, D.; Chatelain, A.; DeHeer, W.A. Nanocapillarity and chemistry in carbon nanotubes. Science 1996, 274, 1897-1899. [CrossRef]

26. Castillejos, E.; Debouttiere, P.J.; Roiban, L.; Solhy, A.; Martinez, V.; Kihn, Y.; Ersen, O.; Philippot, K.; Chaudret, B.; Serp, P. An efficient strategy to drive nanoparticles into carbon nanotubes and the remarkable effect of confinement on their catalytic performance. Angew. Chem. Int. Edit. 2009, 48, 2529-2533. [CrossRef] [PubMed]

27. Zhang, F.; Pan, X.L.; Hu, Y.F.; Yu, L.; Chen, X.Q.; Jiang, P.; Zhang, H.B.; Deng, S.B.; Bolin, J.T.B.; Zhang, S.; et al Tuning the redox activity of encapsulated metal clusters via the metallic and semiconducting character of carbon nanotubes. P. Natl. Acad. Sci. USA 2013, 110, 14861-14866. [CrossRef] [PubMed]

28. Qi, W.; Su, D.S. Metal-free carbon catalysts for oxidative dehydrogenation reactions. ACS Catal. 2014, 4, 3212-3218. [CrossRef]

29. Chen, S.; Wang, S.P.; Ma, X.B.; Gong, J.L. Selective oxidation of methanol to dimethoxymethane over bifunctional $\mathrm{VO}_{x}$ /TS-1 catalysts. Chem. Commun. 2011, 47, 9345-9347. [CrossRef] [PubMed] 